\title{
PREOPERATIVE PREDICTORS OF STERNOTOMY NEED IN MEDIASTINAL GOITER MANAGEMENT
}

\author{
Claudio Casella, MD, ${ }^{1}$ Giacomo Pata, MD, ${ }^{1}$ Carlo Cappelli, MD, ${ }^{2}$ Bruno Salerni, MD ${ }^{1}$ \\ ${ }^{1}$ Department of Medical \& Surgical Sciences, First Division of General Surgery, \\ University of Brescia, Italy. E-mail: giacomopata@alice.it \\ ${ }^{2}$ Department of Medical \& Surgical Sciences, Internal Medicine and Endocrinology Unit, \\ University of Brescia, Italy \\ Accepted 18 September 2009 \\ Published online in Wiley InterScience (www.interscience.wiley.com). DOI: 10.1002/hed.21303
}

\begin{abstract}
Background. The objective of this study was to identify the preoperative risk factors for patients in need of a sternotomy in the management of mediastinal goiters in order to provide better preoperative planning and patient consent.

Methods. We analyzed 98 patients who underwent surgery for mediastinal goiters (goiters extending below the thoracic inlet $\geq 3 \mathrm{~cm}$ with the neck in hyperextension) between 1995 and 2008. Twelve (12.2\%) of the patients required a sternotomy. The patients' features were analyzed by the surgical approach performed. Logistic regression analysis was used to study which variables were influencing the surgical strategy. The receiver operating characteristic (ROC) curves were designed when appropriate.

Results. The analysis disclosed the following risk factors: radiologic extension of mediastinal goiters below the aortic arch (odds ratio $[\mathrm{OR}]=32.87 ; 95 \%$ confidence interval $[\mathrm{Cl}]=$ 4.04-267.12; $p<.0001$ ); posterior mediastinum involvement for mediastinal goiters with subaortic extension $(\mathrm{OR}=7.2$; $95 \% \mathrm{Cl}=1.52-34.14 ; p=.0244)$; history of mediastinal goiters before surgery (for mediastinal goiters aged $>160$ months: $\mathrm{OR}=22.8 ; 95 \% \mathrm{Cl}=5.28-98.53 ; p<.0001$ ).

Conclusions. Sternotomy need for mediastinal goiter removal can be predicted; in such cases surgeons should not hesitate to perform it for minimizing complications. () 2009 Wiley Periodicals, Inc. Head Neck 00: 000-000, 2010
\end{abstract}

Correspondence to: G. Pata

() 2009 Wiley Periodicals, Inc.
Keywords: mediastinal goiter; sternotomy; cervicotomy; thyroid; risk factor

Terms such as retrosternal, substernal, intrathoracic, or mediastinal have been used to describe a goiter that extends beyond the thoracic inlet. Although suppression therapy by exogenous thyroxine can reduce the size of the gland by $20 \%$ to $30 \%,{ }^{1}$ the consensus is that the mediastinal goiter is a condition that requires surgical management. Literature reports often stress the need for surgical treatment in relation to compressive symptoms, potential airway compromise, and the possibility of an association with thyroid malignancy. ${ }^{2-6}$

The mediastinal thyroid can be usually managed through a cervical incision. ${ }^{7}$ This approach has been shown to be sufficient in up to $97 \%$ of cases. ${ }^{5}$ In patients in whom the gland cannot be safely removed through a cervical incision, thyroidectomy may require a thoracic approach to gain adequate exposure and to remove the gland while avoiding dangerous tractions. Unfortunately, there is no clear demarcation of the cases that require a combined approach, and the 
decision to employ it is usually made during surgery.

In order to improve preoperative planning and patient consent, we reviewed our mediastinal thyroid surgery with specific intention to identify clinical, radiologic, or pathologic factors that may predict the need for a thoracic approach.

\section{PATIENTS AND METHODS}

Between January 1, 1995, and December 31, 2008, a total of 893 patients were operated on for thyroid lesions in the Department of General Surgery.

Preoperative workup included physical examination, standard laboratory parameters including thyroid function tests, neck ultrasound, and plain chest roentgenogram. If clinical/ultrasound findings were suspicious for thyroid malignancy, a fine-needle aspiration biopsy was performed, as currently sustained by literature. ${ }^{8,9}$ When mediastinal extension of the goiter was suspected based on preoperative plain chest x-rays and ultrasound findings, neck and chest CT scans were obtained to get an accurate delineation of the goiter size and its relation to the adjacent structures. Those patients having a goiter extending $3 \mathrm{~cm}$ or more below the suprasternal notch by preoperative CT scan evaluation with the neck in hyperextension were classified as having mediastinal goiters. Their charts were reviewed retrospectively to retrieve clinical history, physical and laboratory data, surgical and histologic reports, and any evidence of postoperative complications. Preoperative CT scan analysis has focused on maximal retrosternal area of the goiter (calculated through dedicated software) and its relation to the trachea, esophagus, and major vessels. These data were compared between patients with mediastinal goiter who required a sternotomy (sternotomy group) and those who did not (cervicotomy group). Institutional approval and patients' written informed consent were obtained.

Surgical Technique. The operative procedure started with neck exploration through a Kocher transverse collar incision, after stretching the strap muscles or cutting them, when necessary. The upper thyroid poles were double-legated and transected, and the recurrent laryngeal nerve (RLN) exposed and dissected. Careful dissection was done to ensure mobilization in the correct tissue plane, with care to identify and preserve the parathyroid glands. Upward delivery of the gland was attempted using the index and middle finger. If this maneuver failed, we extended the approach with a partial sternotomy limited to a longitudinal section down to the level of the second or third intercostal space. Neither complete sternotomy nor thoracotomy was performed in any patients, even when the goiter was situated in the posterior mediastinum.

Statistical Analysis. Chi-square or Fisher exact test, when appropriate, were used to compare categorical variables. The Mann-Whitney $U$ test was used to analyze differences in continuous variables (presented as median and range) between 2 groups of patients. Binary logistic regression analysis was used to identify any variable that might influence the main outcome. The receiver operating characteristic (ROC) curves were then designed, and the relative values providing the best prediction for sternotomy need were calculated. Positive and negative likelihood ratios (+LR; -LR) were calculated in order to estimate the relative risks of positive or negative outcome (sternotomy). The level for statistical significance was set at $p<.05$. All tests were 2sided. Statistical analysis was performed with statistical software for biomedical research (McCalc Software for Windows, v 9.2.0.0).

\section{RESULTS}

Ninety-eight patients (11\%) were classified as having mediastinal goiters. No patient had a history of previous thyroid surgery. All of them underwent total thyroidectomy. Sternotomy was required in 12 cases $(12.2 \%)$. There was no significant difference among the 2 groups with regard to patients' age and sex: the median age in the sternotomy group was 64 years (range, 39-80) as compared with 67-years-old (range, 46-81) in the cervicotomy group $(p=.31)$; the male/female ratio was $1 / 2$ in sternotomy versus $21 / 65$ in the cervicotomy group (odds ratio $[\mathrm{OR}]=1.55 ; 95 \%$ confidence interval $[\mathrm{CI}]=0.42-5.67 ; p=.51$ ). The history of known mediastinal goiters in our patients was up to 30 years, and its duration correlated significantly with the need for sternotomy (83-360 months [median, 193] in the sternotomy group vs 44-268 months [median, 99] in the cervicotomy group; $p=.0002$ ). Logistic regression analysis confirmed this correlation. The ROC analysis showed significant area under the curve (Figure 1). History of goiter longer than 160 months correlated 


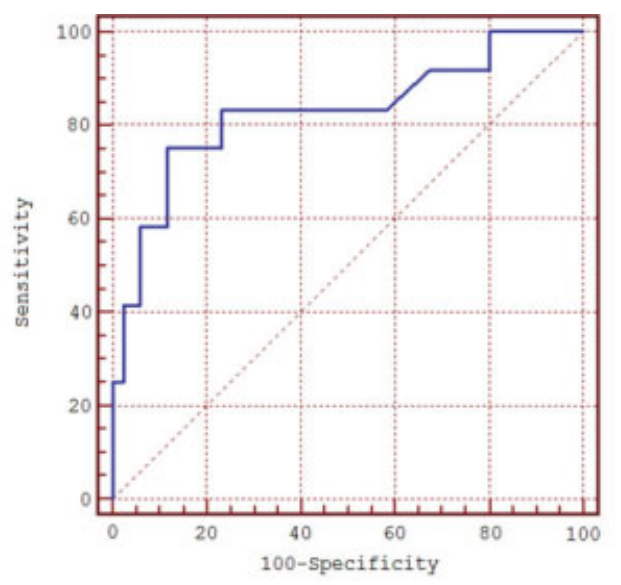

Area under the ROC curve $=0.828$

Standard Error $=0.075$ (958 Confidence Interval $(\mathrm{CI})=0.739-0.897)$

prediction of extracervical access for MGs aged $>160$ months:

-Sensitivity $=758(958 \mathrm{CI}, 42.8-94.2)$

Specificity $=88.48(954 \mathrm{CI}, 79.6-94.3)$

Positive likelihood ratio $(+L R)=6.45$

-Negative likelihood ratio $(-L R)=0.28$

FIGURE 1. ROC curve relative to the substernal goiter history duration (in months). [Color figure can be viewed in the online issue, which is available at www.interscience.wiley.com.]

strongly and positively with the need for sternotomy $(\mathrm{OR}=22.8 ; 95 \%$ CI, 5.28-98.53; $p<.0001)$.

Also, the radiologic extension of the mediastinal goiters below the aortic arch strongly correlated with the need for sternotomy, with an OR of 32.87 (95\% CI, 4.04-267.12). This radiologic finding was evident in all patients who required a sternotomy compared with $27 \%$ in the cervicotomy group $(p<.0001)$, and it predicted the extended approach with sensitivity of $100 \%$ (95\% CI, $73.4 \%$ to $100 \%)$ and specificity of $73.3 \%$ $(95 \% \mathrm{CI}, 62.6 \%$ to $82.2 \%) ;+\mathrm{LR}=3.74 ;-\mathrm{LR}=0$.

The retrosternal extension of the mediastinal goiters was anterior to the trachea and major vessels in 54 patients (55\%) and posterior in 44 patients $(45 \%)$. This radiologic feature was not a predicting factor for sternal incision $(\mathrm{OR}=2.78$; 95\% CI, 0.78-9.94; $p=.129$ ). However, posterior mediastinum involvement by the gland did reveal a further strong predictive factor for sternotomy among patients with mediastinal goiters extending below the aortic arch $(\mathrm{OR}=7.2 ; 95 \%$ CI, $1.52-34.14 ; p=.0244$; Table 1 ).

Preoperative symptoms of cervicotomy versus sternotomy patients are listed in Table 2. No patients in either group were asymptomatic. All sternotomy patients, compared with $79 \%$ of cervicotomy patients, had radiologic evidence of tracheal deviation, compression, or both $(\mathrm{OR}=$ 3.18; 95\% CI, $0.39-26.1 ; p=.116)$. Signs of esophageal involvement at CT scan evaluation (displacement or impingement) were displayed in $75 \%$ of patients in the sternotomy group compared with $61.6 \%$ in the cervicotomy group (OR $=1.87 ; 95 \%$ CI, $0.47-7.4 ; p=.527)$. There was no significant difference $(p=.74)$ between the 2 groups in the average maximum retrosternal area on preoperative CT scan. Neither white blood cell count nor standard laboratory parameters of thyroid function differed significantly between the study groups.

On histologic examination, 83 patients $(96.5 \%)$ had a benign colloid goiter removed through a cervical access, compared with 11 patients $(91.7 \%)$ who required a sternal incision $(\mathrm{OR}=0.4 ; 95 \%$ CI, $0.04-4.16 ; p=.412)$. One patient in each group had a follicular carcinoma. Two patients, both in the cervicotomy group, had Graves-Basedow disease. There was no operative mortality, blood transfusion requirement, need for tracheotomy, or wound infection. Tracheomalacia was revealed by intraoperative assessment in 2 patients in the cervicotomy group. These patients remained intubated for 24 hours with no further complications or need for a tracheostomy. A total of 6 patients had postoperative complications, $5(5.8 \%)$ in the cervical incision group and 1 $(8.3 \%)$ in the sternotomy group $(\mathrm{OR}=1.47 ; 95 \%$ CI, $0.16-13.8 ; p=.553$; Table 3 ). They consisted

Table 1. Preoperative CT features of patients with mediastinal goiter and surgical management performed (cervicotomy vs cervicotomy + sternotomy).

\begin{tabular}{|c|c|c|c|c|c|c|c|c|}
\hline & \multicolumn{4}{|c|}{ Cervicotomy } & \multicolumn{4}{|c|}{ Cervicotomy + sternotomy } \\
\hline & \multicolumn{2}{|c|}{$\begin{array}{l}\text { Lower edge of gland } \\
\text { above/at aortic arch }\end{array}$} & \multicolumn{2}{|c|}{$\begin{array}{c}\text { Lower edge of gland } \\
\text { below aortic arch }\end{array}$} & \multicolumn{2}{|c|}{$\begin{array}{c}\text { Lower edge of } \\
\text { gland above/at } \\
\text { aortic arch }\end{array}$} & \multicolumn{2}{|c|}{$\begin{array}{c}\text { Lower edge of gland } \\
\text { below aortic arch }\end{array}$} \\
\hline & Anter & Poster & Anter & Poster & Anter & Poster & Anter & Poster \\
\hline $\begin{array}{l}\text { No. of patients (\%) } \\
\text { Total }\end{array}$ & \multicolumn{3}{|c|}{86} & $5(6 \%)$ & 0 & 0 & $12^{4(33 \%)}$ & $8(67 \%)$ \\
\hline
\end{tabular}

Abbreviations: Anter, gland located in the anterior mediastinum; Poster, gland located in the posterior mediastinum. 
Table 2. Preoperative clinical features of patients with cervicomediastinal goiter and surgical management performed (cervicotomy vs cervicotomy + sternotomy).

\begin{tabular}{lccc}
\hline Clinical features & Cervicotomy & $\begin{array}{c}\text { Cervicotomy } \\
+ \text { sternotomy }\end{array}$ & $p$ \\
\hline Nocturnal chocking & $52(61 \%)$ & $7(58 \%)$ & n.s. \\
Use of 2 pillows at night & $53(62 \%)$ & $7(58 \%)$ & n.s. \\
Audible breathing & $26(30 \%)$ & $5(42 \%)$ & n.s. \\
Dysphagia & $30(35 \%)$ & $3(25 \%)$ & n.s. \\
Visible upper chest veins & $23(27 \%)$ & $3(25 \%)$ & n.s. \\
\hline
\end{tabular}

Note: Values are presented as number of patients and percentages.

Abbreviation: n.s., value not significant.

of unilateral transient RLN palsy in 3 cases (3.5\%), and unilateral permanent RLN palsy in 1 case $(1.1 \%)$, both observed in patients managed through a cervical access alone, and postoperative bleeding in 2 instances (2\%), 1 in each study group. Persistent hypoparathyroidism was not observed in any of our patients.

\section{DISCUSSION}

Solid criteria have not been established yet for selecting mediastinal goiter patients who would probably require a sternotomy. Data reported by the literature widely vary, likely influenced by the surgeons' experience, referral bias, case complexity, and differences in definition of mediastinal goiters.

Despite the widespread use of CT scans in the preoperative assessment of mediastinal goiters, the correlation between CT scan features and the surgical approach required has been poorly investigated to date. Furthermore, attempts to establish any significant correlation between the patients' clinical features and the actual surgical procedure always proved fruitless. ${ }^{10-14}$ In the present study, we found that extension of the goiter below the level of the aortic arch appeared to be a significant predictive factor for the need for sternotomy, displaying an OR of almost 33. Conversely, the lack of radiologic extension beyond the aortic arch predicted successful transcervical removal of mediastinal goiters without sternotomy. The same finding was previously observed by Grainger et $\mathrm{al}^{15}$ based on CT scan evaluation. However, their results were based on just 3 patients requiring sternotomy out of a rather small cohort (24 patients).

Retrosternal extension of mediastinal goiters with respect to the trachea and major vessels did not appear to be, per se, a predicting factor for sternal incision; however, posterior mediastinum involvement by the gland was found as a further strong predictive factor for sternotomy need when present along with extension of the goiter below the aortic arch.

At CT scan evaluation, the size of the goiter (cross-sectional area) did not vary significantly between the 2 groups, suggesting that the need for a sternotomy is related more to anatomic location than to the actual size of the goiter. Mediastinal goiter history duration was found to be the second parameter significantly correlated to the need for a sternal approach during surgical procedure, with an OR close to 23 for glands aged more than 160 months. This parameter was not considered by Cohen, ${ }^{16}$ who recently remarked the value of subaortic extension and posterior mediastinum involvement as predictors of thoracic access, although based upon a limited number of extracervical procedures performed (4 sternotomies).

It is evident that the definition of mediastinal goiters has a crucial role in determining our results. In this study, we defined mediastinal goiters as only goiters extending below the thoracic inlet by at least $3 \mathrm{~cm}$ at $\mathrm{CT}$ scan evaluation with the neck in hyperextension, as this is 1 of the most widely accepted definitions. ${ }^{10,17,18}$ Nevertheless, studies including only goiters reaching or descending below the aortic arch, ${ }^{12}$ or having $>50 \%$ of the mass located below the thoracic inlet, ${ }^{19}$ or even with any extent of the gland below the thoracic inlet have also been published. ${ }^{20,21}$

If we had used less selective inclusion criteria and comprised goiters with any part of the gland extending below the thoracic inlet (378 thyroids in the same study period), then the duration of mediastinal goiter's history would have not resulted as a risk factor for sternotomy (OR 2.78; $95 \%$ CI $0.95-8.16 ; p=.07$ ), whereas its extension below the level of the aortic arch would have been

Table 3. Postoperative complications (cervicotomy vs cervicotomy + sternotomy).

\begin{tabular}{lccc}
\hline & Cervicotomy & $\begin{array}{c}\text { Cervicotomy } \\
+ \text { sternotomy }\end{array}$ & $p$ \\
\hline $\begin{array}{l}\text { Unilateral transient } \\
\text { RLN palsy }\end{array}$ & $3(3 \%)$ & 0 & n.s. \\
$\begin{array}{l}\text { Unilateral permanent } \\
\text { RLN palsy }\end{array}$ & $1(1 \%)$ & 0 & n.s. \\
$\begin{array}{l}\text { Bleeding } \\
\text { Persistent } \\
\text { hypoparathyroidism }\end{array}$ & $1(1 \%)$ & $1(8 \%)$ & n.s. \\
$\begin{array}{l}\text { Wound infection } \\
\text { Mortality }\end{array}$ & 0 & 0 & n.s. \\
\hline
\end{tabular}

Note: Values are presented as number of patients and percentages. Abbreviations: RLN, recurrent laryngeal nerve; n.s., value not significant. 
an even stronger predictor of sternal incision at operation $(\mathrm{OR}=34 ; 95 \% \mathrm{CI}, 11-104 ; p<.0001)$.

The mediastinal goiter's history in our patients, which ranged from 3.5 to 30 years, is longer than in recent large series published in the English-language literature. ${ }^{22}$ The longstanding nature of the goiter probably leads to the development of intrathoracic vascular and soft tissue connections that can hinder a safe delivery of the gland from behind the sternum through a cervical access alone. Sternal split was shown to be suitable for the delivery of the substernal goiter in all cases in which an extended approach was required, while a further, more invasive approach, such as complete median sternotomy or thoracotomy, appeared unnecessary. The rate of partial median sternotomy reported in this series was $12.2 \%$. This figure is indeed high, but the study was performed at a national referral center for mediastinal goiters.

We found that partial upper sternotomy is a safe procedure, since postoperative complications were similar among patients who underwent cervicotomy with or without sternal incision. This fact recalls a concept already outlined by Sand et $\mathrm{al}^{4}$ who suggested that a more liberal use of sternal access may prevent some postoperative complications, including injury to the RLN, parathyroid glands, adjacent organs, and major hemorrhage caused by excessive traction through a cervical incision.

\section{CONCLUSIONS}

Mediastinal goiters with radiologic evidence of extension below the aortic arch at the tracheal bifurcation were prone to require sternotomy. In these patients, posterior mediastinal extension increased the risk of need for sternotomy. Furthermore, the duration of known mediastinal goiters beyond 160 months was strongly associated with the need for a sternotomy. Sternotomy was observed to have acceptable and similar complications when compared with cervicotomy alone.

Acknowledgment. The authors thank Dr. D. Chiesa, MD, for her continuous support.

\section{REFERENCES}

1. Monchik JM, Materazzi G. The necessity for a thoracic approach in thyroid surgery. Arch Surg 2000;135:467471; discussion 471-472.
2. Shaha AR. Surgery for benign thyroid disease causing tracheoesophageal compression. Otolaryngol Clin North Am 1990;23:391-401.

3. Newman E, Shaha AR. Substernal goiter. J Surg Oncol 1995;60:207-212.

4. Sand ME, Laws HL, McElvein RB. Substernal and intrathoracic goiter. Reconstruction of surgical approach. Am Surg 1983;49:196-202.

5. Sanders LE, Rossi RL, Shahian DM, Williamson WA. Mediastinal goiters. The need for an aggressive approach. Arch Surg 1992;127:609-613.

6. Torre G, Bongonovo G, Amato A, et al. Surgical management of substernal goiter: analysis of 237 patients. Am Surg 1995;61:826-831.

7. Huins CT, Georgalas C, Mehrzad H, Tolley NS. A new classification system for retrosternal goitre based on a systematic review of its complications and management. Int J Surg 2008;6:71-76.

8. de Roy van Zuidewijn DB, Songun I, Hamming J, Kievit J, van de Velde CJ, Veselic M. Preoperative diagnostic tests for operable thyroid disease. World J Surg 1994; 18:506-510; discussion 510-511.

9. Morgan JL, Serpell JW, Chang MS. Fine-needle aspiration cytology of thyroid nodules: how useful is it? ANZ J Surg 2003;73:480-483.

10. Topcu S, Liman ST, Canturk Z, et al. Necessity for additional incisions with the cervical collar incision to remove retrosternal goiters. Surg Today 2008;38:10721077.

11. Ahmed ME, Ahmed EO, Mahadi SI. Retrosternal goiter: the need for median sternotomy. World J Surg 2006; 30:1945-1948; discussion 1949.

12. Cichoń S, Anielski R, Konturek A, Baczyński M, Cichoń W, Orlicki P. Surgical management of mediastinal goiter: risk factors for sternotomy. Langenbecks Arch Surg 2008;393:751-757.

13. Agha A, Glockzin G, Ghali N, Iesalnieks I, Schlitt HJ. Surgical treatment of substernal goiter: an analysis of 59 patients. Surg Today 2008;38:505-511.

14. Erbil Y, Bozbora A, Barbaros U, Ozarmağan S, Azezli A, Molvalilar S. Surgical management of substernal goiters: clinical experience of 170 cases. Surg Today 2004; 34:732-736.

15. Grainger J, Saravanappa N, D’Souza A, Wilcock D, Wilson PS. The surgical approach to retrosternal goiters: the role of computerized tomography. Otolaryngol Head Neck Surg 2005;132:849-851.

16. Cohen JP. Substernal goiters and sternotomy. Laryngoscope 2009;119:683-688.

17. de Perrot M, Fadel E, Mercier O, et al. Surgical management of mediastinal goiters: when is a surgery required? Thorac Cardiovasc Surg 2007;55:39-43.

18. White ML, Doherty GM, Gauger PG. Evidence-based surgical management of substernal goiter. World J Surg 2008;32:1285-1300.

19. Katlic MR, Wang CA, Grillo HC. Substernal goiter. Ann Thorac Surg 1985;39:391-399.

20. Allo MD, Thompson NW. Rationale for the operative management of substernal goiters. Surgery 1983;94: 969-977.

21. Sitges-Serra A, Sancho JJ. Surgical management of recurrent and intrathoracic goiters. In: Clark $\mathrm{OH}$, Duh Q-Y, Kebebew E, (eds). Textbook of Endocrine Surgery, 2nd ed. Philadelphia: Elsevier Saunders; 2005. p. 304317.

22. Hedayati N, McHenry CR. The clinical presentation and operative management of nodular and diffuse substernal thyroid disease. Am Surg 2002;68:245-251; discussion 251-252. 